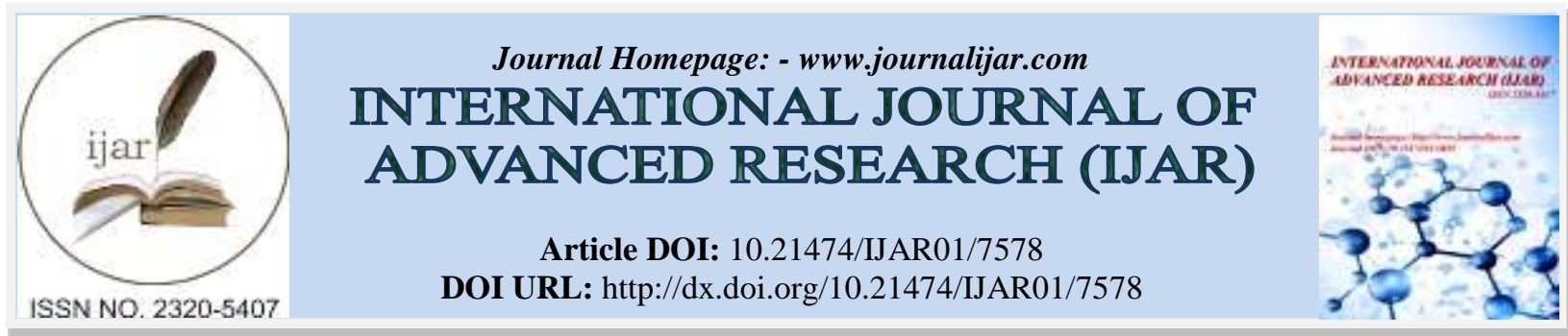

RESEARCH ARTICLE

\title{
IMPROVING LONG ACTING AND REVERSIBLE CONTRACEPTIVES UPTAKE USING QUALITY IMPROVEMENT STRATEGY AT A SUB-COUNTY HOSPITAL KENYA.
}

1. School of Nursing and Midwifery, Masinde Muliro University.

2. Iguhu County Hospital.

3. Kakamega County Referal Hospital.

\section{Manuscript Info}

\section{Manuscript History}

Received: 16 June 2018

Final Accepted: 18 July 2018

Published: August 2018

Keywords:-

FamilyPlanning, LARC, Continuous Quality Improvement, Quality

Improvement (QI).

\section{Abstract}

Introduction: Fertility rates in Sub-Saharan Africa is known to be high than any other region in the world with a Total Fertility Rate (TFR) of 5.1 children per woman. Kenya being one of the Sub-Saharan African country has equally high fertility rate of 3.9 children per woman. Despite the high rates, the uptake of Long acting and Reversible contraceptives (LARC) is low. It is on this basis that the study aimed at improving LARC uptake using continuous Quality improvement strategy (CQI).

Objectives: To improve LARC uptake as a family planning method and to initiate and sustain postpartum LARC within 48 hours by Dec 2016

Methods: It was a hospital based cross sectional study which employed quantitative methods. Study population was all women of reproductive age who came to the facility to seek health services and were eligible for a family planning method. One hundred and fifty women were counselled, guided by the Operations Manual for Staff at Primary Health Care Centres established by WHO in 2008. The study was done in the months of August, September, October and November 2016. Data was collected and analyzed weekly. To analyze the rate of women receiving LARC among women of Reproductive Age, the Numerator was divided by the Denominator and then multiplied by 100 to obtain the rate which was then expressed as a percentage. The same was done to analyze the rate of women receiving LARC 48 hours post-delivery.

Findings: The percentage of women using LARC increased gradually from $17 \%$ noted in baseline survey to about $83 \%$ by the end of the survey in November.Initiation of 48hours postpartum LARC was done and the practice picked gradually from October 2016 when it was initiated to the first week of December 2016 when the project ended with $67 \%$ of women taking a method 48hours after delivery.

Conclusion and Recommendation: With C.Q.I much has been realized especially in care of clients and quality care is guaranteed to all citizens regard-less of their status in the society. It provides a chance to all staff to provide quality health care within their own capacity. Nevertheless, the number of staff should be adequate and all of them should be involved. 


\section{Introduction:-}

Fertility rates in Sub-Saharan Africa is known to be high than any other region in the world with a Total Fertility Rate (TFR) of 5.1 children per woman (Greene, Josh \& Robies, 2012). Studies indicate that about $24 \%$ of married women in Sub-Saharan Africa have an unmet need for family planning. This is defined as the desire to avoid pregnancy for the next two or more years and not utilizing a modern method of contraception (Greene et al., 2012). According to KDHS (2014), Kenya's Total Fertility Rate (TFR) is at 3.9 births per woman. This according to the survey means that a woman in Kenya would bear about four children in her lifetime if fertility were to remain constant at current levels. Despite the unmet need, a number of contraceptive methods are available for women though the effectiveness of different methods varies (Mazza, Black, Taft, \& Lucke, 2017). According to Mazza et al. 2017, permanent methods like vasectomy and tubal ligation exist but they agree that it is generally accepted that long-acting reversible contraceptives (LARCs) which include intrauterine devices (IUDs) and progestogen implants are more effective given their minimal adherence requirements and long duration. Methods such as the oral contraceptives, vaginal ring and condoms also known as Short-Acting Reversible Contraceptives (SARCs) are also available and can be very effective only when strict adherence is consistently maintained (Green, 2012; National Institute for Health and Care, 2014; Mazza et al., 2017). Long Acting and Reversible Contraceptives (LARC) is defined as contraceptive methods that require administration less than once per cycle or month. Included in the category of LARC are: copper intrauterine devices, progestogen-only intrauterine systems and progestogen-only injectable contraceptives (National Institute for Health and Care, 2014).According to National Institute for Children's Health Quality(2016),LARC options, intrauterine devices (IUD) and contraceptive implants is known to represent an opportunity for use by all women of Reproductive age to prevent unintended pregnancies. National Institute for Children's Health Qualityalso state that LARC is easy to use, highly effective, lasts for a number of years and is known to be safe for all women including postpartum and teens.

Despite its effectiveness, studies have revealed that the uptake of LARC is low globally and regionally. This has been attributed to barriers like lack of Health practitioners' knowledge on counseling and master of the skill in administering the method (Mezza et al., 2017; National Institute for Children's Health Quality, 2016). They also agree that other barriers include low patient knowledge, provider misconceptions about LARC usage and risk including a misconception linking IUDs with an elevated likelihood of pelvic inflammatory disease especially to women with multiple partners or those whose partners have multiple partners. In Kenya, KDHS (2014) noted that only $3.4 \%$ and $9.9 \%$ of women seeking family planning method use IUCD and Implants respectively. In Kakamega County the report indicated that only $1 \%$ of the women use IUCD. This is very low given the advantages attached to LARC. Different reasons have emerged as to why the uptake is low but with no data to back up the statement. According to Kakamega District Health Information system (DHIS), most women who deliver in the hospital leave without a family planning method and the reasons given mostly was that the pills would interfere with milk let down and therefore the mother should come back at six weeks for a method. It is on these grounds that the study was found necessary in order to analyze the factors that are contributing to the low uptake of LARC and find the solutions to improving the uptake by using continuous Quality Improvement strategy. The idea came in after CQI training for the staff by the County quality assurance office in July 2016. Iguhu County Hospital MCH department formed a Work Improvement Team which was to analyze the reasons for low uptake and this was done by brain storming. A baseline survey was carried out for the months of April -July and it emerged that only $15.6 \%$ of clients seeking FP services took LARC as an option. The team decided that they would follow up LARC clients among clients seeking FP services as an indicator to improve. The team also decided to focus on LARC 48 hours postpartum in order to improve the LARC indicator in general. LARC 48 hours post-partum had not been initiated in the Health facility

CQI has been used widely in the manufacturing industries with a lot of success. It is a systematic process of identifying, describing and analyzing strengths and problems and then testing, implementing, learning from and revising solutions. This includes the observation of a phenomenon, isolating variables and changing the process, observing the results and taking action. If the results are beneficial, continue with the change and look for the next area to improve. If the results are adverse, discard them and try something else. The results are continuously observed until a pattern of foreseeable results emerges from performing certain actions (Office of Adolescent Health, 2016;Kahan \& Goodstadt, 1999). As stated by Bishop and Dougherty (2004), the best way to service excellence is to have an effective Continuous Quality Improvement (CQI) program which will help in transitioning 
the provider from where he/she is now to where she/he wants to be. CQI uses a structured, cyclical process for developing and implementing change as shown below.

PDSA Cycle by Walter Shewart (2007)

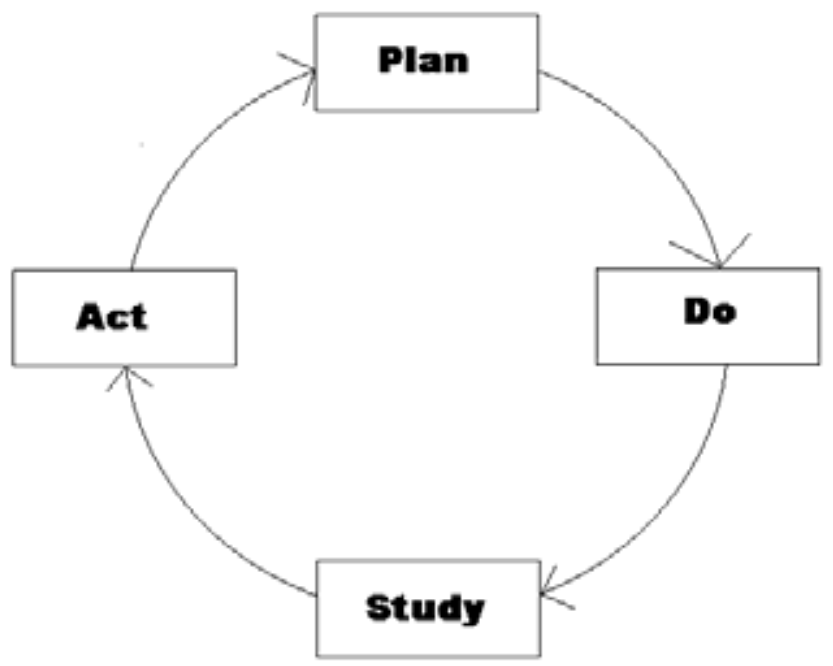

"Plan" means to collect and analyze data and develop solutions. "Do" means to implement one of the proposed solutions. "Study" means to measure any changes as the result of the proposed solution that was implemented, and "Act" means to adopt the solution of standard practice, or start over (Hunter, Ebener, Chinman, Ober \& Huang 2015). This framework has been used with both programs and larger systems and can be very broadly applied.

\section{Materials and Methods:-}

The study was hospital based cross-sectional employing quantitative methods. It was conducted at Iguhu County Hospital which is situated in Kakamega County in Ikolomani Sub County. The study population was all women of reproductive age who brought their children to the well clinic for immunization and were eligible for family planning, all mothers who came for family planning services and all mothers who delivered in the hospital at the period of the study. One hundred and fifty women were sampled guided by the Operations Manual for Staff at Primary Health Care Centres (World Health Organizaton, 2008). According to the manual a simple way to identify the patients to be included in your sample is to divide the total number of eligible patients you have identified in your register(s) or active case list, by the number of patients you need to review, based on the table in appendix I.This therefore means that if you have 750 eligible patients for Family planning indicator, the look-up table tells you that your sample should be 146 . If you divide 750 by 146, the result is five. You will now need to take your ordered list (or patient cards arranged in order of enrolment) and select every fifth patient. The list to use should ensure that each patient is recorded no more than one time. However, given that in Family planning no target setting is done, all the eligible women in the study were sampled.. Permission was sought from the Iguhu County hospital Ethics and Research Committee.

\section{Data collection procedure:-}

It was done twice. The first data collected formed the baseline and the second data collection was done after implementation to measure the effect of implementation and note any improvement.

A baseline survey was done by going through District Health Information System (DHIS) to retrieve four months report (April, May, June, and July) preceding the survey to establish LARC uptake on monthly basis. One of the indicators for measurement was the percentage of women receiving LARC among women of Reproductive Age where the Numerator was the Number of women receiving LARC and the Denominator was the Total Number of women seeking FP services. Another indicator was the percentage of women receiving LARC 48 hours postdelivery. The Numerator was the Number of women receiving LARC $48 \mathrm{hrs}$ post-delivery while the Denominator was the Number of women who delivered in the facility. When the data collection was complete, the rate (score) 
was calculated. The Numerator was divided by the denominator and multiplied by 100 to obtain the rate which was expressed as a percentage. This then formed the baseline rate (score). The results are shown below

Baseline for Clients receiving LARC (IUCD / Implants)

\begin{tabular}{|l|l|l|l|l|}
\hline & APRIL & MAY & JUNE & JULY \\
\hline $\begin{array}{l}\text { LARC } \\
\text { NEW+CONVERTERS) }\end{array}$ & 27 & 23 & 27 & 21 \\
\hline $\begin{array}{l}\text { TOTAL FP (NEW } \\
\text { +REVISTS }\end{array}$ & 152 & 132 & 185 & 163 \\
\hline $\begin{array}{l}\text { PECENTAGE USE OF } \\
\text { LARC }\end{array}$ & 17.76 & 14.59 & 12.90 \\
\hline
\end{tabular}

After establishing the baseline score, a cause and effect quality improvement tool was used to determine where the possible problems were. A decision matrix was used to evaluate and prioritize a list of options. This was done according to Kahan \&Goodstadt (1999) and Bishop \&Dougherty (2004) who stated that for one to arrive at the best option, they must use quality improvement tools like the fish bone, the 5s and the decision matrix among other tools. The decision matrix that was used evaluated and prioritized the options as shown in the table below.

\begin{tabular}{|l|l|l|l|l|l|}
\hline $\begin{array}{l}\text { Potential } \\
\text { performance gaps } \\
\text { to be addressed }\end{array}$ & \multicolumn{5}{|l|}{ CRITERIA: RANK 1-5 where 5=totally meets criteria } \\
\cline { 2 - 6 } & $\begin{array}{l}\text { Issue seen } \\
\text { as important }\end{array}$ & $\begin{array}{l}\text { Realistic } \\
\text { scope } \\
\text { control }\end{array}$ & $\begin{array}{l}\text { Likelihood } \\
\text { of success } \\
\text { via QI }\end{array}$ & $\begin{array}{l}\text { Potential impact } \\
\text { of QI project }\end{array}$ & Total \\
\hline $\begin{array}{l}\text { 1. Low uptake of } \\
\text { LARC as FP } \\
\text { among WRA }\end{array}$ & 4 & 4 & 4 & 3 & 15 \\
\hline 2.Poor client flow & 4 & 3 & 3 & 2 & 12 \\
\hline 3.Misconceptions & 4 & 4 & 5 & 4 & 17 \\
\hline $\begin{array}{l}\text { 4.Lack of } \\
\text { knowledge and } \\
\text { skills on LARC } \\
\text { among staff }\end{array}$ & 5 & 4 & 4 & 5 & 18 \\
\hline
\end{tabular}

Implementation:-

It was based on implementing an improvement model that includes measuring- testing change- re-measuring, and applying change.

Change Concepts:-

\begin{tabular}{|l|l|l|}
\hline Root Cause & 1st Counter measure & 2nd counter measure \\
\hline Myths and misconceptions & Dispel myths and misconceptions & Health talks/Education on LARC \\
\hline $\begin{array}{l}\text { Lack of staff skills on coun-selling } \\
\text { and LARC provision }\end{array}$ & $\begin{array}{l}\text { Improve staff skills on coun-selling } \\
\text { and LARC provision }\end{array}$ & $\begin{array}{l}\text { On-job-training /Mentorship on } \\
\text { LARC }\end{array}$ \\
\hline $\begin{array}{l}\text { Lack of community awareness on } \\
\text { LARC }\end{array}$ & Improve community awareness & $\begin{array}{l}\text { Community involvement- Using } \\
\text { CHVs to teach on LARC }\end{array}$ \\
\hline Poor flow of clients & Improve client flow & $\begin{array}{l}\text { Integration of MCH/FP Services in } \\
\text { one room. }\end{array}$ \\
\hline Poor follow up mechanism & Strengthen follow up mechanisms & $\begin{array}{l}\text { Continuous support supervision } \\
\text { especially by MOH and partners. } \\
\text { Monthly meetings by WIT to revise } \\
\text { strategies put in place. }\end{array}$ \\
\hline $\begin{array}{l}\text { Lack of space in maternity for } \\
\text { PPFP } \\
\text { Lack of FP commodities in } \\
\text { maternity }\end{array}$ & $\begin{array}{l}\text { All postpartum clients to receive FP } \\
\text { Counseling as BCG is being } \\
\text { administered } \\
\text { Initiate a tray containing all FP }\end{array}$ \\
\hline
\end{tabular}




\begin{tabular}{|l|l|l|}
\hline & commodities in maternity & \\
\hline Poor documentation & Improve documentation & \\
\hline
\end{tabular}

The Old Proceess Flow

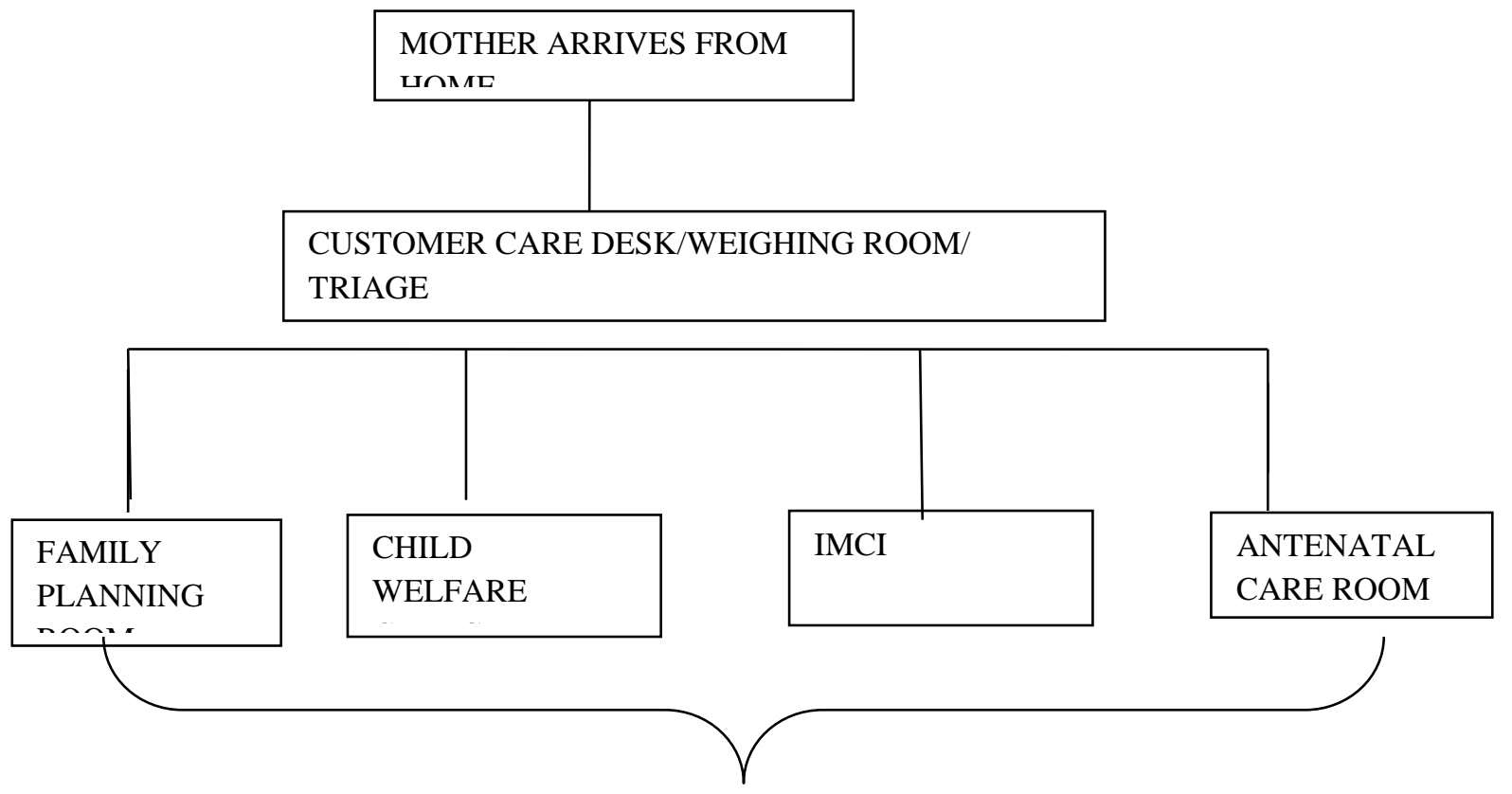

The New Process Flow

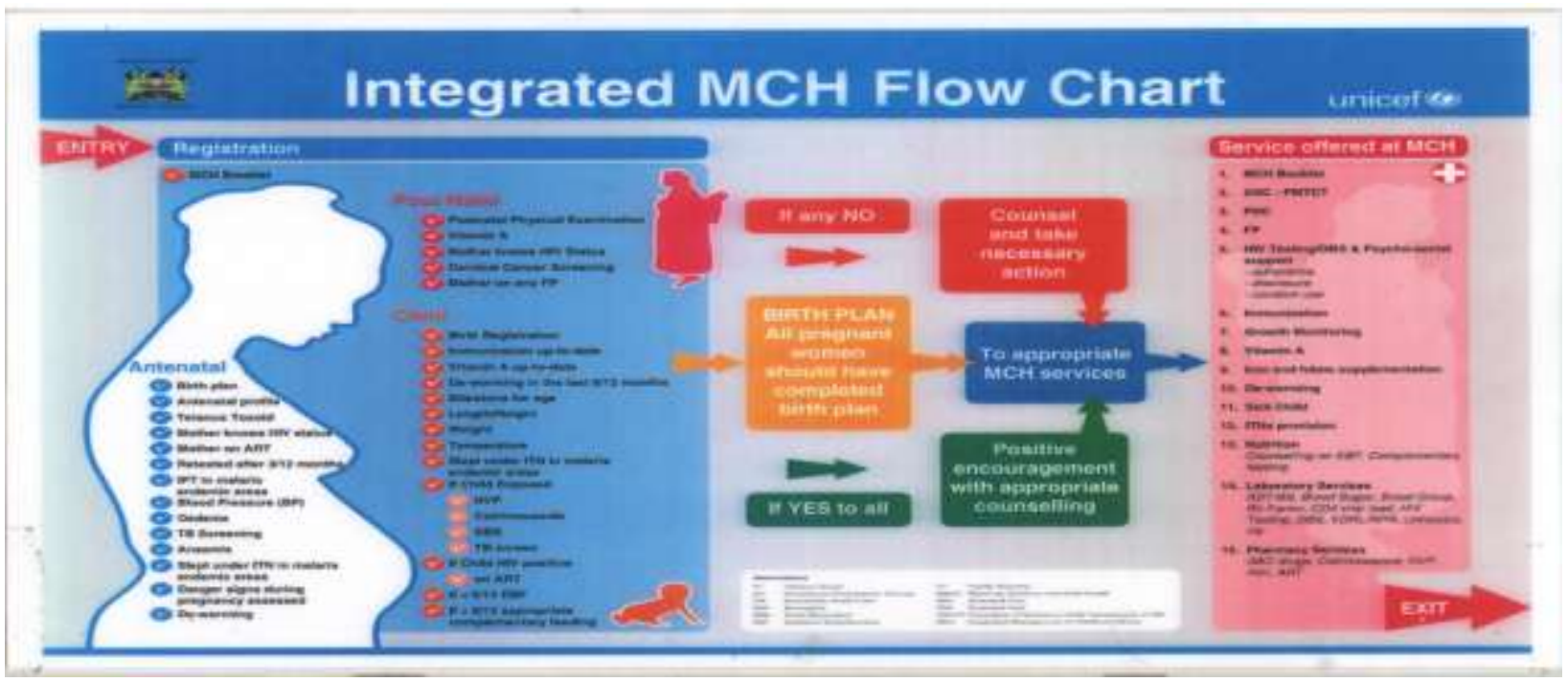

To improve the organization of the environment, Kaizen principles together with the five Ss (5Ss - sort, set in order, shine, standardize and sustain) were applied. Five Ss is the foundation of all improvements and is the key component of establishing a visual workplace. It focuses on having visual order, organization, cleanliness and standardization. This was meant to integrate the services which could in turn improve client flow and reduce waiting time. 

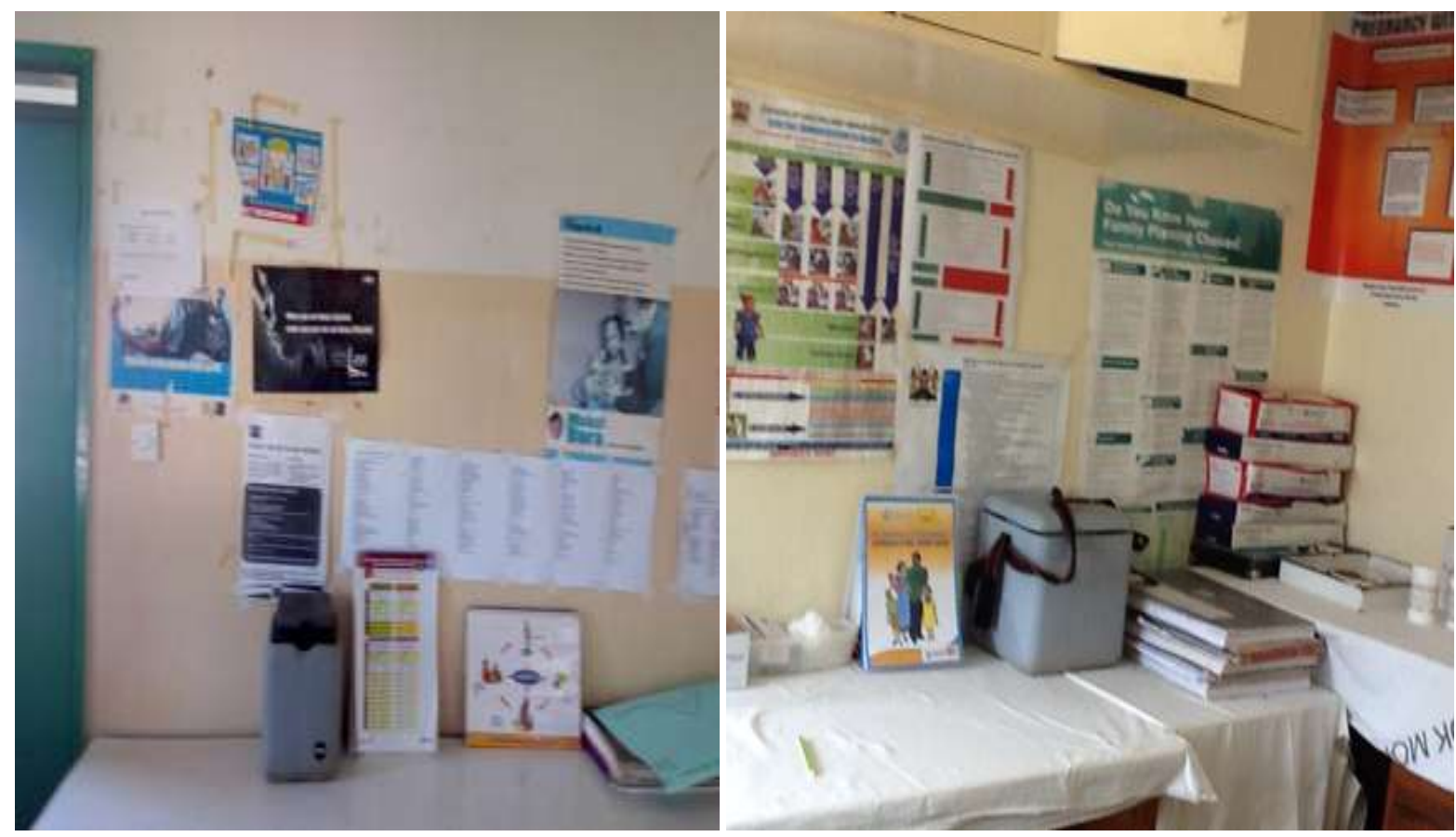

\section{Data collection after Implementation:-}

All the necessary implementation was done as above. The old $\mathrm{MCH}$ flow process was changed and $5 \mathrm{~s}$ (sort, set in order, shine, standardize and sustain) by kaizen applied to organize the environment.

All the services were offered in one room given that the new process flow provided for integration of services. As shown in the diagram above (After 5s) reporting tools were well arranged on the table and these enabled the health provider to document all her work. Data was collected from Family planning registers where all the new clients and the converted clients were recorded for the period of the study. Data collection was done on weekly basis and the results analyzed

\section{Data Analysis:-}

To analyze the rate of women receiving LARC among women of Reproductive Age, the Numerator (Number of women receiving LARC) was divided by the Denominator (Total Number of women seeking FP services and then multiplied by 100 to obtain the rate which was then expressed as a percentage.

To analyze the rate of women receiving LARC 48 hours post-delivery, theNumerator (Number of women receiving LARC $48 \mathrm{hrs}$ post-delivery) was divided by the Denominator (Number of women who delivered in the facility) and then multiplied by 100 to obtain the rate which was expressed as a percentage.

\section{Results:-}

The percentage of women using LARC increased gradually from $17 \%$ noted in baseline survey to about $83 \%$ by the end of the survey in November. 


\section{Results in Improvement:-}

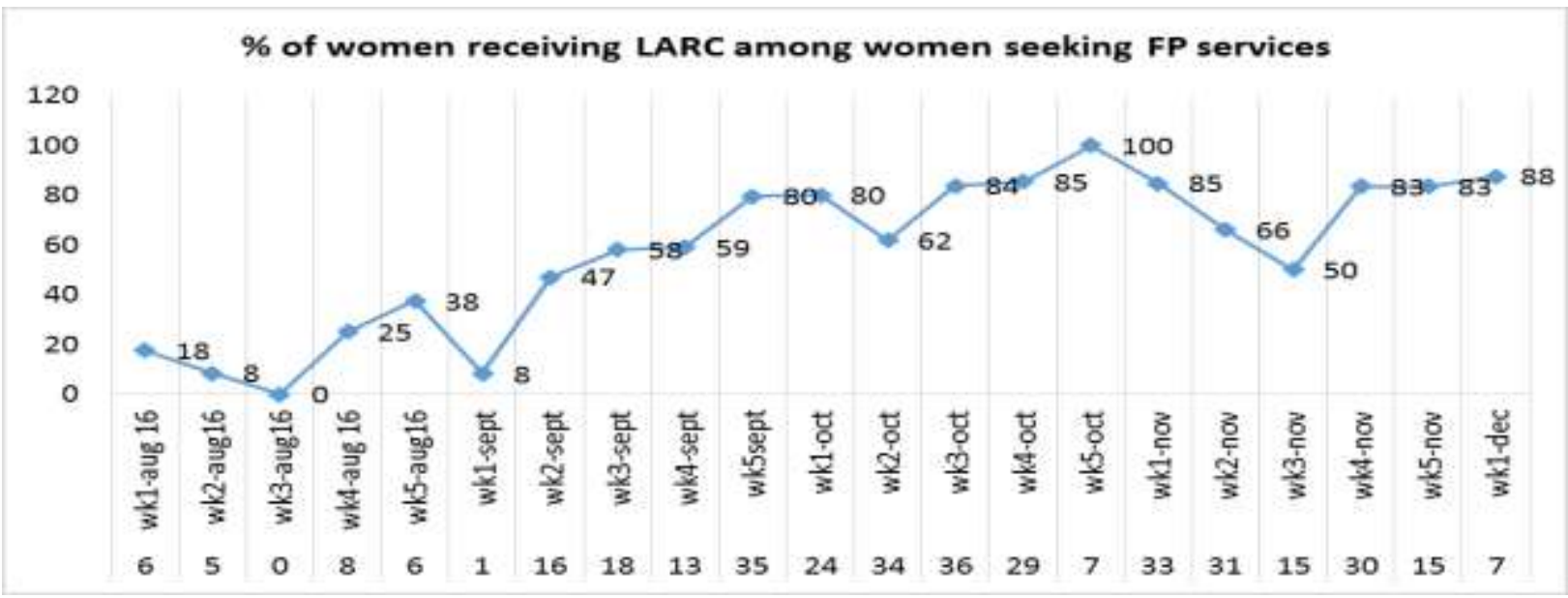

Initiation of 48hours postpartum LARC was done and as shown on the run chart, the practice picked gradually from $29 \%$ in October 2016 when it was initiated to $67 \%$ in the first week of December 2016 when the project ended.

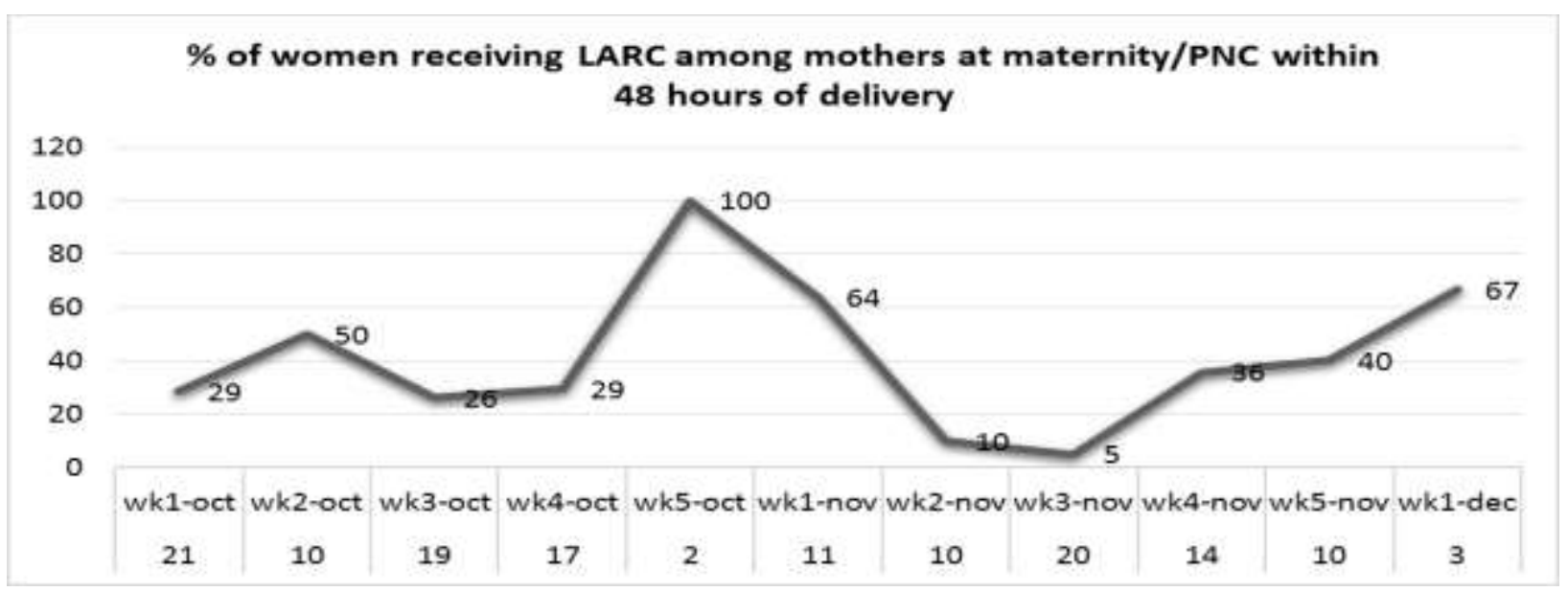

The data was displayed on the wall in the clinic and in maternity ward where everyone could quickly see how the system was working, whether improvements were occurring, or whether they were needed.

\section{Discussion:-}

The percentage of women using LARC increased gradually from $17 \%$ noted in baseline survey to about $83 \%$ by the end of the survey in November. This did not just come at once but gradually as it is seen on the run chart. The improvement is likely to have been due to the implementation of the options that were derived from the decision matrix. These included; changing the process flow to enable integration of services, health education to both health workers and the community, applying the $5 \mathrm{~s}$ to improve the arrangement of the environment which enabled the health workers to document their work easily and also facilitated easy client flow and finally the training of the health workers to improve on their skills in both counseling and providing the method.The results are not unique to this study as other studies have shown that some of the barriers to LARC uptake include lack of skill in providing the method, myths and misconceptions and unavailability of the commodities at the facilities (Weisberg, 2014; Family Health international, 2007; Saunders et al., 2010).According to Weisberg (2014), Saunders et al. (2010), Babalola\&Neetu (2012) and Ringheim (2011), some of the strategies that should be put in place to improve LARC uptake include training the staff on the skill, clearing myths and misconceptions through health education to the community, integration of services and removing financial barriers. 
Initiation of 48hours postpartum LARC was done and as shown on the run chart, the practice picked gradually from $29 \%$ in October 2016 when it was initiated to $67 \%$ in the first week of December 2016 when the project ended. This was a great success given that initially it was not being practiced. By the end of the project the uptake was at $67 \%$ meaning that $67 \%$ of the mothers who gave birth that week were initiated on LARC before discharge. In the last week of October, $100 \%$ of the mothers who delivered in the facility were initiated on LARC. This is attributed to the strategies that were applied through CQI. According to studies done on Quality Improvement and CQI, if the project utilizes the PDSA cycle well, there is always results improvement (Office of Adolescent Health, 2016; Hunter et al., 2015; Implementation guide, 2013). The success of the project is not unique as many institutions which adopted Quality improvement as a method to improve their services and utilized CQI steps correctly had an improvement in their service delivery (Office of Adolescent Health, 2016; Hunter et al., 2015; Implementation guide, 2013; Kahan \& Goodstadt, 1999; Bishop \& Dougherty, 2004)

\section{Lessons Learnt}

- Other people's ideas matter a lot

- Start small and you will achieve big.

- Your attitude determines how well you do it and it's a little thing that makes a big difference.

- When you equip staff with the necessary knowledge and skills they can perform better.

- Team work is very key for every programme to succeed.

- Motivation of staff i.e. use of terms like- 'good, wonderful and you can do even better than this ' really matters in work places

- Increase in LARC uptake is possible if barriers are analyzed and strategies to correct them put in place

\section{Challenges}

- Limited space for integration of services.

- Staff shortage.

- Still some misconception in the community about LARC.

\section{Conclusion:-}

With C.Q.I much has been realized especially in care of clients and quality care is guaranteed to all citizens regardless of their status in the society. It provides a chance to all staff to provide quality health care within their own capacity

\section{Recommendations:-}

- Need for more nurses.

- Continuous Health Education on LARC to promote community awareness.

\section{Next indicators to follow-up}

Improve Cancer screening.

Increase number of clients seeking postnatal care services

\section{Refernces:-}

1. Adrian Bishop, Richard Dougherty (2004). Implementing Continuous Quality Improvement at the Healthcare Provider Level Dougherty Management Associates

2. Babalola, S.,Neetu, J. (2012). Factors Underlying the Use of Long-Acting and Permanent Family Planning Methods in Nigeria: A Qualitative Study.The Respond Project Study Series: Contribution to Global Knowledge. Report No 5

3. Family Health International (2007). Addressing the Unmet Need of Family Planning in Africa.The Case for Long-Acting and Permanent methods.

4. Greene M, Joshi, S., Robles, O. (2012). By Choice, Not by Chance: UNFPA State of the World Population Report.

5. Hunter, S., Ebener, P., Chinman, M., Ober, A, Huang, Y. (2015). Promoting Success. A to Outcomes Guide to Implementing Continuous Quality Improvement for Community Service Organizations. Santa Monica, CA: Rand Corporation. Retrieved from: http://www.rand.org/pubs/tools/TL179.html

6. Kahan, B., \& Goodstadt, M. (1999). Continuous quality improvement and health promotion: Can CQI lead to 
better outcomes? Health Promotion International, 14(1), 83-91. https://doi.org/10.1093/heapro/14.1.83

7. National Institute for Children's Health Quality. (2016). Strategies to Increase Access to Long-Acting Reversible Contraception (LARC) in Medicaid, (May). Retrieved from https://www.nichq.org/sites/default/files/resource-file/IncreasinAccess-To-LARC_CoIIN-NASHP.pdf

8. National Institute for Health and Care. (2014). Long-acting reversible contraception ( update ), (September 2014), 1-44. Retrieved from https://www.nice.org.uk/guidance/cg30/

9. Office of Adolescent Health. (2016). Performance Management http://www.hhs.gov/ash/oah/oahinitiatives/teen_pregnancy/training/performance-_ management.html

10. Ringheim, K., Gribble, J., Foreman M. (2011). Integrating Family Planning and Maternal and Child Health Care: Saving Lives, Money and Time. Policy Brief. Population Reference Bureau

11. Safety Net Medical Home Initiative Implementation Guide, (2013).Quality Improvement Strategy PT 1, Tools to make and Measure Improvement

12. Saunders, M., H. Sethi, A.A. Jayachandran, and Sharma, S. (2010). A Policy Response to Increase Access to Family Planning Services for the Poor in Jharkhand, India. Washington, DC: Futures Group, Health Policy Initiative, Task Order 1.

13. Weisberg, E. (2014). Promoting the Use of Long-Acting Reversible Contraceptives. Austin J Obstet Gynecol. 2014;1(6): 6.

14. World Health Organizaton. (2008). Infrastructure. Operations Manual for Delivery of HIV Prevention, Care and Treatment at Primary Health Centres in High-Prevalence, Resource-Constrained Settings Edition 1 for Field-Testing, 60-65.

Appendix I:-Sample size Calculation

Operations Manual for Staff at Primary Health Care Centres (WHO, 2008).

\begin{tabular}{|c|c|}
\hline Population size upto 20 & Sample Size/All \\
\hline 30 & 26 \\
\hline 40 & 32 \\
\hline 50 & 38 \\
\hline 60 & 43 \\
\hline 70 & 48 \\
\hline 80 & 53 \\
\hline 90 & 57 \\
\hline 100 & 61 \\
\hline $101-119$ & 67 \\
\hline $120-139$ & 73 \\
\hline $140-159$ & 78 \\
\hline $160-179$ & 82 \\
\hline $180-199$ & 86 \\
\hline $200-249$ & 94 \\
\hline $250-299$ & 101 \\
\hline $300-349$ & 106 \\
\hline $350-399$ & 110 \\
\hline $400-449$ & 113 \\
\hline $450-499$ & 116 \\
\hline $500-749$ & 127 \\
\hline $750-999$ & 131 \\
\hline $1000-4999$ & 146 \\
\hline 5000 or more & 150 \\
\hline
\end{tabular}

